\title{
Análise do instituto do amicus curiae à luz da teoria do agir comunicativo
}

\author{
Victor Jácomo da Silva ${ }^{1}$ \\ Mariana Reis Caldas ${ }^{2}$
}

Resumo: O presente trabalho pretende investigar, à luz do pensamento do filósofo contemporâneo Jürgen Habermas, quais as implicações do instituto jurídico do amicus curiae no processo judicial de controle abstrato de constitucionalidade exercido pelo Supremo Tribunal Federal, a fim de oferecer uma avaliação sobre o sentido e alcance da abertura democrática promovida pela incorporação do instituto na dinâmica contraditória das esferas do Poder do Estado.

Palavras-chave: amicus curiae; teoria do agir comunicativo; controle de constitucionalidade; democracia.

\section{Analysis of the amicus curiae institute in the light of the theory of communicative action}

Abstract: The present work intends to investigate, in light of the thought of the contemporary philosopher Jürgen Habermas, the implications of the amicus curiae legal institute in the judicial process of abstract control of constitutionality exercised by the Federal Supreme Court in order to offer a consequent evaluation of the sense and scope of the democratic opening due to the incorporation of the institute in the contradictory dynamics of the spheres of State Power.

Keywords: amicus curiae; theory of communicative action; control of constitutionality; democracy.

\section{Introdução}

O Brasil possui um refinado modelo de controle de constitucionalidade. Os três poderes estão implicados nesse sistema: primeiro momento, o Legislativo, ao submeter seus projetos de leis às suas comissões de constituição e justiça e ao valer-se da prerrogativa inscrita no inciso X do art. 52 da Constituição Federal; em segundo lugar o Executivo, quando lança mão do chamado veto jurídico sobre o projeto de lei que lhe chega para avaliação; e o

\footnotetext{
${ }^{1}$ Graduado pelo Centro Universitário de Barra Mansa - Unidade Cicuta. Mestrando em Direito pelo UNISAL Centro Universitário Salesiano de São Paulo - Lorena em Concretização dos Direitos Sociais, Difusos e Coletivos. Advogado.

${ }^{2}$ Mestranda em Direito pelo UNISAL - Centro Universitário Salesiano de São Paulo - Lorena em Concretização dos Direitos Sociais, Difusos e Coletivos. Advogada
} 
Judiciário em terceiro é ultimo momento. E, é exatamente nessa esfera do poder do Estado em que se podem observar os mecanismos mais elaborados de controle de constitucionalidade.

O controle judicial de constitucionalidade pode ser dividido em controle por via de ação e por via de exceção, ou seja, a verificação de compatibilidade vertical das leis e atos normativos pode dar-se como instrumento de defesa contra normas inconstitucionais invocadas por sujeitos em situação contenciosa ou, ainda, por meio de ações autônomas que visam a declaração da posição da norma infraconstitucional em relação à Constituição. Essas ações são: a) Ação Direta de Inconstitucionalidade Genérica (ADI ou ADIn), prevista no art. 102, inciso I, alínea 'a', da CF/88; b) Ação Direta de Inconstitucionalidade Interventiva (ADIn Interventiva), prevista no art. 36, inciso III, da CF/88; c) Ação Direta de Inconstitucionalidade por Omissão (ADIn por Omissão), prevista no art. 103, § $2^{\circ}$ da CF/88; d) Ação Declaratória de Constitucionalidade (ADCon), prevista no art. 102, inciso I, alínea 'a', da CF/88; e, por fim, c) Arguição de Descumprimento de Preceito Fundamental (ADPF) prevista no art. 102, $\S 1^{\circ}$, da CF/88.

Tais ações, via de regra, culminam em decisões judiciais erga omnis, ou seja, decisões judiciais cujos efeitos são gerais e abstratos, oponíveis a todos. Esse caráter geral e abstrato da decisão judicial inaugura uma tensão na lógica republicana ao atribuir à decisão judicial os mesmos atributos das leis.

A questão que se impõe é: como preservar a lógica democrática valendo-se de um sistema de controle de constitucionalidade em que membros não eleitos da sociedade, desvinculados dos compromissos propriamente políticos, atuam como legisladores, mesmo que legisladores apenas negativos, entendidos assim por sua prerrogativa de extirpar do sistema jurídico normas declaradas inconstitucionais?

Este artigo, partindo dessa questão, pretende analisar o instituto jurídico do amicus curiae à luz do pensamento de Jürgen Habermas, a fim de compreender o que a abertura desse canal de comunicação dentro do judiciário representa em termos de democratização do controle de constitucionalidade.

\section{O problema da atuação do Judiciário como legislador negativo}

A questão da legitimidade da ingerência judicial passa necessariamente pela investigação das formas estabelecidas de expressão democrática da soberania popular. 
A tradição política democrática na modernidade ocidental, com raízes nos ideários do século XVIII, se estrutura a partir da afirmação de certos direitos fundamentais, conhecidos como direitos de primeira geração, os quais abrem o espaço político para o desenvolvimento histórico dos direitos fundamentais. Ao lado disso, foi indispensável pensar formas de organização e funcionamento do Estado, tendo em vista a proteção desses direitos e a participação popular.

Diante da impossibilidade, nos grandes Estados, de participação direta de todas as pessoas nas decisões políticas, a partir das fortes influências do pensador inglês John Locke, o ocidente assumiu a proposta política de democracia parlamentar.

De acordo com Dalmo de Abreu Dallari (1991, p. 123):

No 'Segundo Tratado sobre o Governo' sustentara LOCKE a supremacia do poder legislativo, que poderia ser exercido por vários órgãos, mas sempre sujeito ao povo. A comunidade conserva perpetuamente o poder supremo de salvaguardar dos propósitos e atentados de quem quer que seja, mesmo dos legisladores. E quem detiver o poder legislativo ou o poder supremo de qualquer comunidade obriga-se a governá-la mediante leis estabelecidas, promulgadas e conhecidas do povo.

A separação dos poderes inscrita no art. 16 da Declaração dos Direitos do Homem e do Cidadão de 1789 (“A sociedade em que não esteja assegurada a garantia dos direitos nem estabelecida a separação de poderes não tem constituição”), somada à afirmação da proposta de democracia parlamentar, veio a consubstanciar o panorama geral da política ocidental dos últimos três séculos.

O problema do caráter democrático do Judiciário, quando atua como legislador negativo, aumenta em profundidade nos ordenamentos jurídicos em que este poder não tem seus cargos assumidos por cidadãos eleitos.

Segundo Jürgen Habermas (2010, p. 299):

A competência para essas duas últimas funções (recursos constitucionais) é problemática, ao menos sob pontos de vista da divisão de poderes. Aqui o tribunal constitucional funciona no sentido da uniformização do direito. (...) constitui órgão máximo que assume tarefas de reflexão e autocontrole. De modo semelhante, cabe ao governo, na qualidade de órgão máximo do executivo, a tarefa do autocontrole da administração.

Assim, frequentemente se deparam com demandas judiciais que o convocam a apresentar respostas que antecipam ou substituem as soluções que deveriam ser alcançadas pala via legislativa. Esse é exatamente o panorama brasileiro nos dias atuais.

\subsection{A tensão entre legislativo e judiciário no cenário nacional}


Há quatro razões pelas quais a ordem jurídica nacional provoca esse tipo de sobreposição e, por vezes, tensão entre as funções do Poder Público (FONTE, 2013).

De acordo com Felipe de Melo Fonte (2013, p. 162-163):

Quanto às políticas públicas em particular, este emaranhado resulta do conjunto de razões exposto a seguir: (i) a possibilidade de submeter qualquer questão ao Poder Judiciário devido à cláusula de acesso à jurisdição; (ii) a expansão dos instrumentos e dos legitimados a provocar a jurisdição constitucional concentrada, assim como a tutela coletiva de direitos; (iii) a possibilidade de que todos os juízes, mesmo os de primeiro grau de jurisdição, efetuem o controle de constitucionalidade das normas e atos administrativos; e (iv) a técnica das normas programáticas utilizada na Constituição Federal de 1988.

A primeira das razões cinge-se ao Direito fundamental à inafastabilidade da apreciação pelo Poder Judiciário, também chamado de princípio do acesso à Justiça ou, ainda, princípio do direito de ação.

Tal princípio consubstancia a ideia de que toda pessoa tem o direito de ser ouvida por um tribunal independente e imparcial na defesa de seus direitos. Esse princípio também vincula a atividade legislativa, visto que veda a feitura de qualquer lei que inviabilize a tutela jurisdicional, preventiva, repressiva, de direito individual, difuso coletivo ou individual homogêneo, não obstante, não signifique que está garantido no ordenamento jurídico pátrio o acesso indiscriminado ao Poder Judiciário (BULLOS, 2012, p. 265).

Outro dado de suma relevância sobre a inafastabilidade é que o acesso à jurisdição independe do prévio esgotamento das instâncias administrativas, fazendo escoar para o judiciário mais um imenso número de demandas por direitos cassados pelas instâncias clássicas da política.

Nessa esteira, podemos nos referir à preciosa lição do professor Fredie Didier Jr. (2012, p. 119):

A constituição é peremptória: não há matéria que possa ser excluída da apreciação do Poder Judiciário - ressalvadas raríssimas exceções por ela mesma postas [...] (art. 52, I e II da CF/88) [...]. Esta última característica é a que aqui nos interessa: atualmente, fala-se em tutela jurisdicional adequada. O princípio da inafastabilidade garante uma tutela jurisdicional adequada à realidade da situação jurídico-substancial que lhe é trazida para solução. Ou seja, garante o procedimento, a espécie de cognição, a natureza do provimento e os meios executórios adequados às peculiaridades da situação de direito material.

A segunda razão trás à baila o recente fenômeno da supressão do monopólio de ação de controle concentrado de constitucionalidade conferido ao Procurador-Geral da República e a ampliação substancial do rol de legitimados ativos para demandas dessa natureza. 
A redação originária do art. 103 da CF/88 dispunha como legitimados para propor a referida ação: o Presidente da República, a Mesa do Senado Federal, a Mesa da Câmara dos Deputados, a Mesa de Assembleia Legislativa, o Governador de Estado, o Procurador-Geral da República, o Conselho Federal da Ordem dos Advogados do Brasil, partido político com representatividade no Congresso Nacional e confederações sindicais ou entidades de classe de âmbito nacional.

A Lei 9.868/99, que dispõe sobre o processo e julgamento de ADIn e ADCon, fez constar expressamente o que já se extraia pela melhor exegese do art. 103 da CF/88. Assim, em seu art. $2^{\circ}$, a Lei 9.868/99 previu a legitimidade ativa do Governador do Distrito Federal e da Câmara Legislativa Distrital.

O rigor expresso no texto legal deu causa a previsão na Emenda Constitucional $n^{\circ}$. 45/04 dos referidos legitimados do Distrito Federal.

Sobre a proposta do constituinte de 1988 em ampliar o rol de legitimados ativos em ações de controle abstrato de normas, comentam os autores Hely Lopes Meirelles, Arnoldo Wald e Gilmar Ferreira Mendes (2013, p. 380):

A extensa lista de legitimados para a ação direta de inconstitucionalidade também fortalece
a impressão de que o constituinte pretendeu reforçar o controle abstrato de normas no
ordenamento jurídico brasileiro, como peculiar instrumento de correção do sistema geral
incidente.

A terceira razão responsável por instaurar da tensão entre o judiciário e as clássicas instâncias da política cinge-se à possibilidade constitucionalmente garantida de que qualquer juiz ou tribunal possa declarar a inconstitucionalidade de uma norma jurídica, o que nos interessa neste trabalho.

Por fim, a quarta razão a ser avaliada é referente ao caráter programático da Constituição Federal de 1988.

É sabido que a Constituição prevê amplo rol de direitos individuais e coletivos que imprime no Estado o dever de prestações positivas em favor do povo, de grupos e de pessoas.

Conforme o filósofo Jürgen Habermas (2010, p. 309):

(...) a antiga diferença qualitativa entre legislação e jurisprudência desaparece. Ambas formam direito no modo da concretização e, ao mesmo tempo, concorrem nisso. Nesta relação de concorrência, o legislador dá o primeiro lance, porém o tribunal constitucional detém a primazia... A questão envolvida aí é a da legitimação democrática do tribunal constitucional.

A tese paradigmática do neoconstitucionalismo, segundo a qual tais direitos são judiciáveis, ou seja, passiveis de serem defendidas em juízo, criou o ambiente em que o 
judiciário tem o poder de provocado, obrigar o poder público a garantir um direito que deveria ser alcançado pela via legislativa e executiva, mas não, que não o foi por desídia do Poder Público.

Observamos, portanto, que o ordenamento jurídico positivo nacional, em certa medida, consubstancia aqueles pontos de tensão entre o Legislativo e o Judiciário, o que vale dizer que as contradições aqui abordadas são inerentes ao próprio sistema, apesar de se aprofundarem ainda mais nas suas relações com as outras esferas da sociabilidade.

\subsection{O instituto do Amicus Curiae e o problema do controle abstrato de constitucionalidade}

Um ponto nodal da tensão entre legislativo e judiciário é o já referido controle abstrato de constitucionalidade.

O efeito vinculante e a natureza geral e abstrata da norma inscrita na decisão judicial são as principais razões técnicas para a compreensão da tensão.

De acordo com HABERMANS (2010, p. 309), “a diferença qualitativa precedente, entre legislar e a jurisdição, é nula. Ambos, Legislativo e Judiciário, desenvolvem o Direito, sob a forma de sua concretização, e competem entre si ao fazê-lo”.

A diferença essencial entre a função legislativa e a jurisdicional situa-se apenas em relação à forma, ao processo de produção. Cabe então a questão: como fazer da atuação jurisdicional que implica um “legislar” negativo, uma atuação mais democrática?

Para responder a essa questão, o direito nacional importou em seu sistema o instituto do amicus curiae. A expressão latina significa “amigo da corte” e designa a atuação de sujeito processual, não identificado com a figura da parte, que contribui com a formação do convencimento do órgão julgador, trazendo ao processo informações úteis a melhor apreciação da causa. O instituto do amicus curiae, desse modo, apresenta-se como instrumento para a democratização da jurisdição constitucional.

A origem do instituto remonta o direito medieval inglês, no qual esse sujeito, escolhido arbitrariamente pelo juiz, vinha ao processo para trazer matérias de fato desconhecidas pela corte, como expressão do poder instrutório do juiz.

Mais adiante, a figura do amicus curiae moderniza-se e se fixa no modelo de comommon law, no direito Norte-Americano, para só muito recentemente ser importado também para o Brasil.

Revista de Teorias da Justiça, da Decisão e da Argumentação Jurídica | e-ISSN: 2525-9644 | Salvador | v. 4 | n. 1 | p. 80 - 95 | 
Incialmente há de se delimitar com clareza o funcionamento desse novo instituto.

A lei federal 9.686/99, em seu art. $7^{\circ}, \S 2^{\circ}$, assim estabelece:

\begin{abstract}
Art. 7o Não se admitirá intervenção de terceiros no processo de ação direta de inconstitucionalidade.

$[\ldots]$

§ 2o O relator, considerando a relevância da matéria e a representatividade dos postulantes, poderá, por despacho irrecorrível, admitir, observado o prazo fixado no parágrafo anterior, a manifestação de outros órgãos ou entidades.
\end{abstract}

Posteriormente a lei 10.259 de 2001, dispôs sobre a possibilidade de atuação do amicus curiae em procedimentos em que haja juízo de constitucionalidade concreto.

Do ponto de vista processual, o amicus curiae não pode ser encarado como parte. Não lhe são outorgados os direitos básicos como o de produzir provas, recorrer, contestar, peticionar, alegar nulidades, etc. No Brasil, ao amigo da corte é reservada apenas a prerrogativa de manifestar-se no processo por meio da apresentação de memoriais e sustentações orais.

Buscamos até aqui delinear a tensão institucional existente entre o Poder Legislativo e o Poder Judiciário e compreender o estatuto jurídico da figura do amicus curiae, que, a princípio, parece representar uma abertura democrática nesse campo polêmico que é a possibilidade de o judiciário atuar como legislador negativo.

Cabe, agora, uma investigação mais acurada sobre a pertinência desse instituto no propósito de democratização da jurisdição constitucional.

\title{
3 As contribuições de Jürgen Habermas para a discussão sobre a legitimidade democrática do controle abstrato de constitucionalidade
}

Destacando que as decisões jurisdicionais devem satisfazer, simultaneamente, a critérios de segurança do direito e da aceitabilidade racional, o filósofo alemão Jürgen Habermas aponta a seguinte questão: “(...) de que modo tal prática de interpretação pode operar no âmbito da divisão de poderes do Estado de Direito, sem que a justiça lance mão de competências legisladoras? (HABERMANS, 2010).

Habermas toma por objeto de sua análise do tema o papel e legitimidade da jurisdição constitucional, salientando de início que a existência de tribunais constitucionais não é autoevidente e suas competências são sempre polêmicas.

Segundo os autores Virgílio Afonso Silva e Conrado Hübner Mendes (2008, p. 203):

Revista de Teorias da Justiça, da Decisão e da Argumentação Jurídica | e-ISSN: 2525-9644 | Salvador | v. 4 | n. 1 | p. 80 - 95 | 
[...] embora seja refratário ao papel que o judiciário tem no controle da legislação da maioria dos Estados democráticos contemporâneos, Habermas aborda o problema de forma diferenciada, e distingue diversas formas de crítica à jurisdição constitucional.

De início, pode-se afirmar que a divisão republicana do poder, fundada em uma teoria da argumentação, aponta para uma atividade autorreflexiva do legislativo, ou seja, caberia ao próprio legislativo a avaliação sobre sua própria atividade legiferante.

Habermas compreende que o parlamento não disporia da prerrogativa de examinar se o judiciário, no controle abstrato da constitucionalidade, ao valer-se dos argumentos estritamente jurídicos, não necessariamente respeitaria a racionalidade da fundamentação de uma lei produzida segundo os valores democráticos.

Nesse sentido, afirma Jürgen Habermas (2010, p. 300-301):

[...] a lógica da divisão dos poderes não pode ser ferida pela prática de um tribunal que não possui os meios de coerção para impor suas decisões contra a recusa do parlamento e do governo. A concorrência do tribunal constitucional com o legislador legitimado democraticamente pode agravar-se no âmbito do controle abstrato de normas. E, para saber se uma lei decidida pelo parlamento é conforme a constituição, ou ao menos não contradiz à configuração coerente do sistema de direitos, esta questão é submetida a um reexame judicial. Até a votação, esta é uma questão que o parlamento tem que decidir. É sempre útil considerar se o reexame desta decisão parlamentar também poderia dar-se na forma de um autocontrole do legislador, organizado em forma de tribunal, e institucionalizado, por exemplo, numa comissão parlamentar que inclui juristas especializados. Tal internalização da autorreflexão (...) teria vantagem a vantagem de levar o legislador a manter presente, o conteúdo normativo de princípios constitucionais (...). Nesta linha, se a diferenciação institucional autorreferencial de um processo de controle de normas, fosse da competência do parlamento, talvez pudesse contribuir para o incremento da racionalidade do processo de legislação.

A atuação judicial pressupõe colisões e, em última instância, suas decisões tem caráter principiológico.

Assim, em determinadas situações, há mais de um direito oriundo dos estatutos positivos do Estado, incidente sobre a mesma situação fática. Isso provoca o aprofundamento da indeterminação do direito, afinal, ele não se identifica com a totalidade das leis escritas.

\subsection{Os paradigmas liberais e republicanos}

As análises habermasianas sobre os modelos liberais e republicanos de Estado contribuem sobremaneira para a discussão acerca da jurisdição constitucional por proporcionar uma visão estrutural da relação entre os objetivos do Estado e os valores e princípios insculpidos em seu sistema positivo.

O modelo liberal de interpretação do Direito é marcado pela existência de máximas de interpretação não questionadas, que servem de "normas de fundo”, de forma a conceber um direito aplicável à seu tempo sem necessidade de se recorrer a princípios. 
Ademais, a categoria do indivíduo ganha prevalência sobre a coletividade, desobrigando o Estado de apresentar soluções aos problemas sociais não apreensíveis pela lógica individual.

Consoante Jürgen Habermas (2010, p. 304-305):

Na linha do modelo liberal de sociedade, a constituição deveria fazer uma separação entre a
esfera de uma sociedade econômica, livre do Estado, na qual os indivíduos buscam sua
felicidade e seus próprios interesses de forma autônoma e privada, e a esfera estatal da
persecução do bem comum - "em todo caso não era função da constituição combinar a
esfera do bem individual e do bem comum sob uma ideia de conteúdo mais abrangente”.
Tarefas e objetos do Estado continuavam entregues à política; na compreensão liberal, eles
não eram objeto da normatização do direito constitucional. A isso corresponde a
compreensão dos direitos fundamentais como direitos de defesa, referidos ao Estado. Uma
vez que eles fundamentam apenas pretensões dos cidadãos contra o Estado, que se omite
em relação a eles, valem "imediatamente”.

A divisão clássica dos poderes do Estado, no liberalismo, é seguida de forma rigorosa, pois, em razão de sua matriz histórica, se impõe como forma de controlar o arbítrio do poder estatal absolutista.

Ocorre que Habermas se posiciona de forma bastante refratária à proposta liberal de Estado. A ideia de que a garantia do sistema de direitos se daria de forma espontânea pela soma de decisões tomadas autonomamente pelos indivíduos livres, orientados por interesses egoístas, evidentemente não procede, em especial quando tratamos de sociedades complexas que demandam uma racionalidade organizadora dos conflitos cada vez mais aprofundados.

Nesse passo, explica Jürgen Habermans (2010, p. 307-308):

(...) o sistema de direitos não pode mais ser garantido na base tradicional de uma sociedade econômica liberada, que se reproduz espontaneamente através das decisões particulares autônomas privadas, devendo, ao invés disso, ser concretizado através das realizações de um Estado que dirige reflexivamente, que prepara infraestruturas e afasta perigos, que regula, possibilita e compensa. No entanto, está fora de dúvida que existe uma mudança na conceitualização dos direitos fundamentais, que se reflete na jurisprudência constitucional uma mudança nos princípios de uma ordem jurídica que garantem a liberdade e a legalidade da intervenção, que sustentam os direitos de defesa e transportam inexplicavelmente o conteúdo de direitos subjetivos de liberdade para o conteúdo de direitos subjetivos de liberdade para o conteúdo jurídico objetivo de normas de princípio, enérgicas e formadoras de estruturas. A essa mudança correspondem, sob pontos de vista metodológicos, “conceitos-chave do direito constitucional” (Denninger), tais como, por exemplo, o princípio da proporcionalidade, a reserva do possível, a limitação de direitos fundamentais imediatamente válidos, através dos direitos fundamentais de terceiros, a proteção dos direitos fundamentais através de organização e procedimentos etc. Em caso de colisão, eles servem para relacionar diferentes normas, tendo em vista a "uniformidade da constituição": "Com o desenvolvimento dos conceitos-chave relacionais, o Tribunal Constitucional Federal reconheceu e destacou - no interior de certos limites - a estrutura 'aberta' da constituição da Lei Fundamental”. 
O paradigma republicano, ao passo que promove uma “remoralização” do Direito, o qual não mais se limita apenas à contenção do poder Estatal, convoca o judiciário a uma abertura para argumentações morais de princípios e argumentos políticos, "as normas de princípio, que ora perpassam a ordem jurídica, exigem uma interpretação construtiva do caso concreto, que seja sensível ao contexto e referida a todo o sistema de regras.” (HABERMAS, 2010, p. 305-306).

Tal situação lança as bases para o desenvolvimento do fenômeno do ativismo judicial, o qual seria, em tese, capaz de mediar os ideais republicanos e a prática degenerada da política liberal.

Contudo, essa postura de expansão do sistema judiciário sobre o mundo da vida subverte de forma lesiva o caráter deontológico das normas jurídicas, fazendo avultar o caráter teleológico presente nos princípios, degenerando a característica principal do ordenamento jurídico, qual seja, a codificação binária, afastando-se a racionalidade baseada na díade válido/inválido.

\subsection{A crítica ao sopesamento de valores na jurisdição constitucional}

Habermas identifica dois problemas principais sobre a jurisdição constitucional.

O primeiro deles é a dicotomia empobrecida que há no debate político atual, que orbita entre a proposta liberal, marcada pela degeneração, e a republicana, marcada pela idealização de seus postulados.

O segundo refere-se à jurisdição constitucional orientada pela jurisprudência de valores. Tal método de interpretação constitucional parte do pensamento de Robert Alexy e, na visão de Habermas, implicaria no recurso a uma racionalidade não pertencente à função jurisdicional.

De acordo com Virgílio Afonso Silva e Conrado Hübner Mendes (2008, p. 210):

Ao invés de uma racionalidade baseada na díade válido/inválido, o recurso a valores (ou a princípios) implicaria uma racionalidade estranha ao mundo jurídico, baseada em uma "codificação gradual", ancorada em relações de precedência. Isso porque valores não estipulam deveres ou direitos definitivos aos seus destinatários, mas apenas uma relação de precedência entre si. Em vista disso, valores não teriam a vinculação absoluta de uma obrigação universal e inconstitucional.

Sendo assim, esse método de interpretação constitucional impossibilitaria a manutenção da coerência interna de um sistema normativo, implicando, necessariamente, a 
existência de deveres contraditórios e frustrando a finalidade última da jurisdição constitucional: a estabilização do Direito.

Consoante Jürgen Habermans (2010, p. 302):

Pouco importa o modo como nos posicionamos em relação à questão da institucionalização adequada dessa interpretação da constituição, que diz respeito diretamente à atividade do legislativo: a concretização do direito constitucional através de um controle judicial da constitucionalidade serve, em última instância, para a clareza do direito e para a manutenção de uma ordem jurídica coerente.

A proposta de Robert Alexy, ao orientar a interpretação constitucional pela noção de otimização, minaria a díade válido/inválido, que já vimos ser o estrutural da atividade jurisdicional, e lançaria o sistema positivo em incertezas, nas quais, eventualmente, direitos fundamentais padeceriam no confronto com argumentos teleológicos ou com o interesse coletivo.

“As decisões do Tribunal Constitucional Federal qualificam os direitos fundamentais como princípios de uma ordem jurídica geral, cujo conteúdo normativo estrutura o sistema de regras em seu todo”. (HABERMAS, 2010, p. 307).

Admitir que não há o que se reformular quanto a jurisdição constitucional amparada no sopesamento de valores, seria o mesmo que admitir que os direitos fundamentais seriam meras normas subjetivas e imprecisas que variariam segundo a discricionariedade dos julgadores não legitimados democraticamente.

Diante disso, podemos concluir que o recurso ao sopesamento de valores, segundo a teoria de Alexy, por não apontar para nenhum critério racional e relegar a decisão à arbitrariedade do julgador (HABERMAS, 2010, p. 321-322), "seria tão irracional quanto o debate na arena política, quanto o debate no legislativo” (SILVA E MENDES, 2008, p. 213).

Portanto, o apelo à racionalidade da jurisdição constitucional orientada pelo critério de sopensamento de valores não é bastante para alçá-lo ao status de melhor exegese para o controle de constitucionalidade e, ademais, não atende ainda ao critério democrático.

Interpretando o pensamento do filósofo alemão, asseveram os autores Virgílio Afonso Silva e Conrado Hübner Mendes (2008, p. 213):

(...) a decisão judicial sobre a forma de conciliar a luta por preferência de valores tão diversos - vida, segurança, liberdade, propriedade - nada mais seria do que a visão peculiar de um juiz, que não mais disporia do arsenal típico da argumentação jurídica, e que, por isso, decidiria de forma totalmente arbitrária.

O quanto avançamos até aqui ainda requer uma leitura sobre como o instituto do amicus curiae, que a princípio parece apontar para uma maior democratização da jurisdição 
constitucional, pode verdadeiramente contribuir para uma solução do problema democrático que ronda o controle de constitucionalidade.

\section{0 instituto do amicus curiae à luz da teoria do agir comunicativo}

A teoria do agir comunicativo de Habermas lança um olhar sobre as relações sociais que enfoca a linguagem como amalgama entre os sujeitos. Assim, processos sociais são compreendidos a partir dos atos de fala, das relações do âmbito da linguagem, travadas entre os sujeitos.

A ação comunicativa, por sua vez, encara os atos de fala como meios para a produção de mútuo entendimento entre os sujeitos sociais. Esse mútuo entendimento funda-se principalmente nas pretensões de validade dos agentes sociais que, ao se colocarem em atos comunicativos, assumem o ônus de sustentarem, no âmbito discursivo, suas pretensões (LEAL, 2009, p. 406).

A noção de agir comunicativo de Habermas pode ser melhor compreendida se esclarecermos a noção de sistema e mundo da vida, como referência às estruturas que dão base ao desenvolvimento das ações comunicativas e instrumentais.

Nesse sentido, explica Marcos Nobre (2010, p. 22):

O domínio da vida social em que predominam as ações de tipo instrumental é chamado por Habermas de 'sistema', ao passo que o domínio da vida social em que predominam as ações de tipo comunicativo recebe o nome de 'mundo da vida'.

Segundo Habermas, o advento das sociedades modernas implicou numa separação entre esses dois domínios. Assim, pode-se dizer que os conflitos sociais se processam hoje, em termos de um conflito entre a razão instrumental e razão comunicacional.

Há ainda falar em um processo de colonização do mundo da vida pelo sistema, ou seja, um esvaziamento da esfera pública, onde impera a razão comunicativa, em 
benefício da expansão das esferas burocráticas do mercado e do Estado em sua face menos democrática (NOBRE, 2010, p. 22-23).

É nesse contexto que a teoria do agir comunicativo, ganha relevância como forma de fazer frente a essa colonização que seria capaz de destruir a própria sociabilidade moderna.

Para os fins deste trabalho, cabe anotar que as situações sociais que emergem no contexto da jurisdição constitucional inauguram sempre um palco para contradições sociais de primeira grandeza. Nesse ponto, um aspecto importante do pensamento de Habermas ganha relevo a partir da seguinte pergunta: como se pode garantir as condições mínimas para que agentes sociais diferentes, com interesses contraditórios, possam empreender atos comunicativos com resultados pautados na compreensão mútua, dentro do processo jurisdicional?

Aqui duas questões entram em cena: o conceito de direito pertinente a teoria de Habermas como consenso mínimo, como um pressuposto comunicativo; e o procedimento deliberativo como fator impulsionador do advento do melhor argumento.

Inicialmente, quanto à concepção de direito empregada por Habermas em sua teoria, temos o seguinte: remete-se ao “direito positivo moderno, que se apresenta como pretensão a uma fundamentação sistemática, bem como a uma interpretação e a uma imposição obrigatória” (HABERMAS, 2010, p. 110).

Dizer em uma “fundamentação sistemática” implica em uma justificação fundada em procedimentos garantidores da abertura democrática e que preservem o caráter deontológico das normas em jogo.

Conforme Jürgen Habermas (2010, p. 142):

...uma interpretação apoiada numa teoria do discurso insiste em afirmar que a formação
democrática da vontade não tira sua força legitimadora da convergência preliminar de
convicções éticas consuetudinárias, e sim de pressupostos comunicativos e
procedimentos, os quais permitem que, durante o processo deliberativo, venham à tona os
melhores argumentos.

A presença dos elementos comunicativos nos processos judiciais de jurisdição constitucional, em especial aqueles notadamente marcados pelas implicações políticas, deve ser estimulada ao máximo, respeitados os limites procedimentais garantidores da democracia, pois sem tais elementos “a política seria apenas sistema (e, portanto, 
funcionaria unicamente pela lógica instrumental), o que faria com que ela definhasse até o ponto em que o conjunto dos cidadãos não mais fosse capaz de reconhecer qualquer legitimidade à ordem de dominação vigente” (NOBRE, 2010, p. 24).

A teoria de do agir comunicativo, aplicada no direito, preserva a natureza deliberativa dos processos políticos envolvidos na jurisdição constitucional, ao mesmo tempo que também resguarda a natureza deontológica das normas jurídicas, firmadas como consenso mínimo e objetivo, tudo com vistas à construção de procedimentos organizados e justos para a atuação comunicativa dos agentes sociais envolvidos.

\section{Considerações finais}

A proposta de abertura democrática do processo de jurisdição constitucional por meio da atuação do amicus curiae representa um avanço relativo e extremamente tímido para discussão no judiciário de questões gerais.

Habermas já se posiciona de forma bastante refratária a atuação jurisdicional no controle de constitucionalidade, propondo que tal deveria se fazer por uma atividade autorreflexiva do próprio legislativo, preservando o caráter democrático necessário às decisões dessa natureza.

Se faz necessário que os atores estejam incluídos na discussão judicial no tribunal constitucional, na mesma forma que deve agir na sociedade.

Ademais, o judiciário, ao valer-se do sopesamento de valores, invadiria seara estranha a sua atuação, incidindo em arbitrariedades injustificadas.

Ocorre que, apesar dessas ressalvas, a jurisdição constitucional é uma realidade em dezenas de nações, dentre elas, o Brasil, onde o modelo de controle de constitucionalidade, somado à natureza programática da Constituição Federal e às tendências de aprofundamento do ativismo judicial, colocam os juízes em lugar social proeminente do ponto de vista político. Portanto, não se pode fugir das discussões sobre formas de democratização de tais procedimentos.

Sendo assim, entendemos que o instituto do amicus curiae pode contribuir de forma tímida para a democratização do processo jurisdicional constitucional. Isso porque, conforme seu estatuto legal, sua participação ou não fica relegada à 
discricionariedade do julgador, sem que se estabeleçam critérios objetivos para tanto, além de limitar a possibilidade recursal sobre o despacho autorizador de tal intervenção.

Quanto a função do amicus curiae, nota-se novamente uma diminuta importância, posto que esse se manifestará apenas por meio de memoriais ou sustentações orais, negando-se o direito de petição, apresentações de provas, recursos, etc.

Por fim, não se pode falar em um amadurecimento democrático, por meio dessa inovação legislativa, se não houver uma profunda reformulação dos procedimentos atinentes ao controle de constitucionalidade de forma a reposicioná-lo na esfera do legislativo e, mesmo que tal proposta não seja possível, há de se repensá-lo para privilegiar o caráter deontológico das normas jurídicas, afastando-se, assim, o arbitrário sopesamento de valores.

Firmados esses pontos de depõem contra a afirmativa de que o novo instituto representaria uma verdadeira abertura democrática no processo de jurisdição constitucional, cumpre registrar que, por outro lado, ao menos serve a uma qualificação do debate existente no mundo da vida sobre os grandes temas polêmicos da política nacional. No Brasil, ações de controle abstrato de constitucionalidade ganham espaço privilegiado na mídia, inclusive com transmissões ao vivo de sessões de julgamento.

Concluímos, desse modo, que a contribuição do novo instituto restringe-se a, eventualmente, fazer avultar a esfera pública, abrindo canais de comunicação hábeis a qualificar o debate, e, só indiretamente, representando uma força contrária à colonização do mundo da vida pelo sistema e sua razão instrumental.

Revista de Teorias da Justiça, da Decisão e da Argumentação Jurídica | e-ISSN: 2525-9644 | Salvador | v. 4 | n. 1 | p. 80 - 95 | 


\section{Referências}

BULOS, Uadi Lammêgo. Curso de Direito Constitucional. $7^{\text {a }}$ ed. São Paulo: Saraiva, 2012.

CANOTILHO, José Joaquim Gomes; MENDES, Gilmar Ferreira; SARLET, Ingo Wolfgang; SATRECK, Lenio Luiz (org.); COUTINHO, Aldacy Rachid et al. Comentários à Constituição do Brasil. São Paulo: Saraiva, 2013.

DALLARI, Dalmo de Abreu. Elementos de teoria geral do Estado.15a ed. São Paulo: Saraiva, 1991.

DIDIER JR. Fredie. Curso de Direito Processual Civil v. 1: Introdução ao Direito Processual Civil e Processo de Conhecimento. 14 a ed. Salvador: JusPodium, 2012.

FONTE, Felipe de Melo. Políticas Públicas e Direitos Fundamentais: Elementos de fundamentação do controle jurisdicional de políticas públicas no Estado Democrático de Direito. São Paulo: Saraiva, 2013.

HABERMAS, Jürgen. “Direito e Democracia”: Entre facticidade e validade. Trad. Flávio Beno Siebeneichler. Rio de Janeiro, 2010.

LEAL, R. G. Jurgen Habermas. In BARRETO, V. (Coord.). Dicionário de Filosofia do Direito. Rio de Janeiro, 2009, pp. 403-408.

MEIRELLES, Hely Lopes; MENDES, Gilmar Ferreira; WALD, Arnoldo. Mandado de Segurança e ações constitucionais. 35 ed. São Paulo: Malheiros, 2013.

NOBRE, Marcos. “introdução”. In NOBRE, Marcos e TORRES, Ricardo (org.). Direito e Democracia: Um guia de leitura de Habermas. São Paulo: Malheiros, 2008, pp.15-35.

REPA, Luiz Sérgio. “Direito e Teoria da Ação Comunicativa”. In NOBRE, Marcos e TORRES, Ricardo (org.). Direito e Democracia: Um guia de leitura de Habermas. São Paulo: Malheiros, 2008, pp. 55-71.

SILVA, Virgílio Afonso e MENDES, Conrado Hübner. "Habermas e a Jurisdição Constitucional”. In NOBRE, Marcos e TORRES, Ricardo (org.). Direito e Democracia: Um guia de leitura de Habermas. São Paulo: Malheiros, 2008, pp.198-222.

STRECK, Lenio Luiz. Jurisdição constitucional e decisão jurídica. $4^{\mathrm{a}}$ ed. São Paulo: Editora Revista dos Tribunais, 2014. 